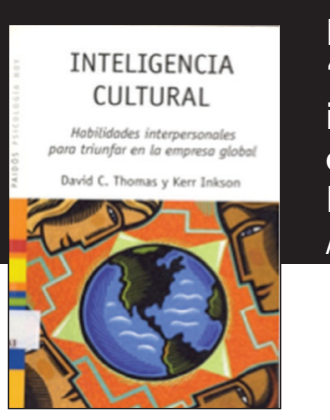

David C. Thomas y Kerr Inkinson. "Inteligencia cultural. Habilidades interpersonales para triunfar en la empresa global". Editorial Paidós. 257 páginas. Año 2007.

\title{
Inteligencia cultural. Habilidades interpersonales para triunfar en la empresa global
}

El libro de los autores David C. Thomas y Kerr Inkinson, elaborado en el año 2007, Inteligencia cultural. Habilidades interpersonales para triunfar en la empresa global, está dividido en nueve capítulos en los que se ilustra con varios ejemplos de conducta transcultural los fundamentos de la Inteligencia Cultural. Parte de la premisa de que cada vez se hace más necesario adaptarse a los intercambios entre diferentes culturas; y que tales intercambios se dan como resultado de los procesos de globalización de los negocios y de las personas, por lo que se considera que todos somos ejecutivos globales.

Se define la Inteligencia Cultural como la capacidad de interactuar de manera eficaz entre personas de orígenes culturales distintos; la Inteligencia Cultural capacita para reconocer las diferencias culturales por medio de su conocimiento y la plena conciencia sobre estas diferencias, y permite actuar de forma apropiada en situaciones transculturales. La Inteligencia Cultural posee tres componentes: conocimiento, para entender los fenómenos; plena conciencia para interpretar situaciones diversas, y habilidad para adaptar el comportamiento y actuar de forma apropiada y satisfactoria en una amplia variedad de situaciones; asimismo, se describen las características que propician la Inteligencia Cultural, entre las que se destacan: la integridad, la receptividad y la resistencia.

Los autores consideran que el primer paso para desarrollar la Inteligencia Cultural es el conocimiento de lo que es la cultura y como ésta varía y afecta el comportamiento de los individuos; para ello, definen la cultura como la mezcla de valores, actitudes y presunciones sobre el comportamiento, compartidos por personas de grupos específicos.

Se identifican cinco fases necesarias para el desarrollo de la Inteligencia Cultural: fase 1) reacción a estímulos externos; fase 2 ) reconocimiento de otras normas culturales y motivación para saber más cosas de las mismas; fase 3) dar cabida a otras normas y reglas culturales; fase 4) asimilación 


\section{LIBROS}

de normas culturales distintas e integración de las mismas en conductas alternativas; fase 5) proactividad en la conducta cultural basada en el reconocimiento de las señales cambiantes que otros no perciben.

El proceso de desarrollo de la Inteligencia Cultural implica que se debe aprender de las interacciones sociales; esto constituye una forma muy productiva de que las experiencias individuales se transfieran al conocimiento y habilidades de los demás. Este aprendizaje supone que se debe poner atención a la situación, retener el conocimiento adquirido a partir de la situación, reproducir las habilidades sociales observadas y finalmente reforzar la eficacia de la conducta adaptada.

Entre las actividades que propician el desarrollo de la Inteligencia Cultural, se destaca que la manera más importante probablemente sea pasar tiempo en el extranjero y adquirir de ese modo una experiencia transcultural, esto se puede lograr al trabajar para una empresa internacional, estudiar en el extranjero, realización de prácticas internacionales, enseñar idiomas en el extranjero, entre otras actividades; sin embargo, se identifican otras actividades que son de suma importancia para el desarrollo de la Inteligencia Cultural, por ejemplo: la formación académica profesional, formación de grupos y equipos multiculturales y las interacciones transculturales en el país de origen.

El estudio resulta relevante, en tanto que al vivir en un mundo globalizado, se convierte en una necesidad desarrollar y aplicar los principios de la Inteligencia Cultural, ya que con ello se conseguirá una mayor eficacia en la toma de decisiones, en la comunicación y negociación entre culturas, en el liderazgo y la motivación y en el desarrollo de una carrera profesional en el ámbito internacional. 